\title{
THE IMPACT OF ERP ON MAINTENANCE MANAGEMENT
}

\author{
Sławomir Kłos, Justyna Patalas-Maliszewska \\ University of Zielona Góra, Institute of Management and Production Engineering, Poland \\ Corresponding author: \\ Stawomir Klos \\ University of Zielona Góra \\ Institute of Management and Production Engineering \\ Prof. Szafrana 4, 65-526 Zielona Góra, Poland \\ phone: (+48) 68 3282464 \\ e-mail: s.klos@iizp.uz.zgora.pl
}

Received: 10 June 2013

Accepted: 17 August 2013

\begin{abstract}
This paper presents a methodology for implementation of an ERP system in the area of production maintenance. The methodology is based on integration of monitoring maintenance events, manufacturing data registration and an employee motivation system.. The maintenance processes discussed in the paper encompass activities in the area of disaster recovery, overhauls, changeovers and special equipment production. This methodology requires implementation of an effective system of data registration and the design of a motivation system for maintenance staff based on the registered data. The models of the maintenance processes are proposed and the illustrative examples are given.
\end{abstract}

KEYWORDS

Enterprise Resource Planning, Computerized Maintenance Management, maintenance management, maintenance processes.

\section{Introduction}

In the last 15 years ERP systems have become a basic tool supporting company management. Implementing an integrated information system in a production company enables efficient decision making in all areas of company activity at operational, tactic and strategic levels. In order to support decision making, it is necessary to implement the ERP system properly. This, however, depends on an adopted methodology. Integrated information systems supporting Enterprise Resource Planning have become a standard in large and many medium-sized companies. All ERP systems available on the market are based on the MRP II (Manufacturing Resource Planning) standard, which facilitates procurement planning, stock management, and balancing of the production capacity [1]. The MRP II standard is intended for supporting serial and diversified production on the assumption that some components are repeatable. It is particularly important for many SMEs which plan to improve production by investing in information systems. ERP or ERP II systems available today encompass a number of addi- tional modules that go far beyond the MRP II standard. They include also CRM (Customer Relationship Management), SCM (Supply Chain Management), SRM (Supplier Relationship Management), PLM (Product Lifecycle Management), HR (Human Resource), CMM (Computerized Maintenance Management) and auxiliary e-business applications [2]. Major ERP suppliers, such as SAP and Oracle, offer modules suitable for project management. They are, however, expensive solutions intended for implementing large projects. A considerable expansion in functionalities of ERP systems covering various functional areas of a business increases their complexity, and therefore makes their operation and implementation more difficult. The complexity of issues related to building, selecting and implementing ERP systems attracted many researchers to examine them. Today ERP systems can support business processes in all functional areas of a manufacturing company. Examples of operating business processes supported by ERP are presented in the Table 1 [3].

In a highly automated industry realizing make-toorder or make-to-stock production, supporting production maintenance with ERP functionality is es- 
sential for the effective production management. The main functions of maintenance comprise:

- repairs planning,

- tools management,

- spare parts warehouse management,

- maintenance personal management,

- maintenance cost management.

Table 1

Examples of business processes supported by ERP systems.

\begin{tabular}{c|l}
\hline $\begin{array}{c}\text { Functional } \\
\text { area }\end{array}$ & \multicolumn{1}{c}{\begin{tabular}{c}
\multicolumn{1}{c}{ Business process supported } \\
bRP systems
\end{tabular}} \\
\hline \multirow{4}{*}{$\begin{array}{c}\text { Sales } \\
\text { and Maketing }\end{array}$} & Market research \\
\cline { 2 - 2 } & Sales plan preparation and monitoring \\
\cline { 2 - 2 } & Prices and discounts management \\
\cline { 2 - 2 } & Customer inquiries registration \\
\cline { 2 - 2 } Supply & Regaration of sale offers \\
\cline { 2 - 2 } Management & Preparation of sale orders \\
\cline { 2 - 2 } & Sales representative management \\
\cline { 2 - 2 } & E-business \\
\cline { 2 - 2 } & Material Requirement Planning \\
\cline { 2 - 2 } & Analysis and selection of suppliers \\
\cline { 2 - 2 } & Warehouse management \\
\cline { 2 - 2 } & Distribution management \\
\cline { 2 - 2 } & Control of material flow \\
\cline { 2 - 2 } Mroduction & Developing bill of materials \\
\cline { 2 - 2 } Management & Developing technological specification \\
\cline { 2 - 2 } & Production planning and scheduling \\
\cline { 2 - 2 } & Registration of production orders \\
\cline { 2 - 2 } & Balancing production capacity \\
\cline { 2 - 2 } & Computerized Maintenance Management \\
\hline
\end{tabular}

To support the maintenance processes by an ERP system, the productions planning functionality must be implemented. Overhauls of a production line or other critical manufacturing resources require the inclusion of repair tasks into the master production schedule. An overhaul can be treated as a special production order or project that needs materials (spare parts) and labor. Maintenance projects can be evaluated in a long time perspective by the analysis of costs or time reduction [4]. Typical indexes dedicated to maintenance activity evaluation in manufacturing enterprises include:

- OEE - Overall Equipment Effectiveness,

- OCE - Overall Craft Effectiveness,

- MTTR - Mean Time to Repair,

- MTTF - Mean Time to Failure,

- MTBR - Mean Time Between Repair.

To calculate the value of the indexes, the time of failures must be measured. To collect data of different production events, many enterprises, especially with high level [5] of automation, use Manufacturing Execution System - MES or ERP functions designed for the production process control and monitoring. The systems are often integrated with Programmable Logic Controllers, which deliver data directly from the production system.

This paper discusses an implementation methodology of ERP systems in the area of production maintenance. The methodology is focused on the improvement of maintenance department activity by motivation integration system with ERP functionality, what corresponds with assumption of transformational leadership theory [6]. The main goal of the article is analyze of maintenance processes and proposition of ERP system implementation methodology in area of production maintenance, based on the effective staff motivation. In part two, an employee motivation system for the maintenance department is proposed. The third part of the paper presents the analysis of maintenance processes in a selected manufacturing enterprise. Finally, the paper presents the methodology of ERP implementation in the maintenance area. The illustrative examples are given.

\section{Effective management of maintenance staff}

Maintenance specific modeling decisions are; component or system perspective and finite or infinite planning horizon [7]. In highly automated production systems professional employees of maintenance departments decide about effectiveness of avoiding and removing breakdowns and failures of production systems. Maintenance departments usually employ specialists in the field of automatic, electronic, robotic, production and mechanical engineering. Management of the maintenance staff is not easy because the planning is often disturbed by accidents, breakdowns and damage to production resources [8]. The system breakdowns are not possible to foresee, and it is not possible to predict whether the reparation will be completed in 10 minutes, 10 hours or 10 days. To effectively manage the maintenance department, the motivation system should be well suited to the specifics and requirements of the company [9].

Many companies make a bonus for maintenance personnel conditional on OEE, which is an important indicator calculated as the total production time for the planned production time. But, in order to use the OEE system to evaluate the maintenance staff effectiveness, a lot of data in on-line mode must be collected. In small or medium enterprises with no industry networks that connect production lines and automatically register production events, it is difficult to register delays or small machine breakdowns. 
In order to properly evaluate effectiveness of maintenance staff, the following data must be registered and analyzed [10]:

- real work time of maintenance,

- time to spend for different categories of maintenance activities,

- production events (breakdowns, repairs, renewal, upgrades, etc.),

- effectiveness of the maintenance activity, individual evaluation of the maintenance activities.

On the base of the data, the motivation system for maintenance department can be constructed. To illustrate the relations between ERP system implementation in maintenance area and the maintenance staff motivation system, a case study of a production enterprise is presented. To implement ERP system in the enterprise models of typical maintenance processes are prepared and analyzed.

Consider a middle enterprise Alpha that produces prefabricated products for building trade. The manufacturing system is highly automated and the enterprise needs a maintenance specialist. The staff of maintenance department not only prevents or removes breakdowns of the production system, but also produce special equipment (tools, patterns, gears, etc.) for the production [11].

The Alpha company implemented ERP system in area of maintenance, but to better support the maintenance activities, the functionality of ERP should improve the motivation system in this area.

The greatest value created for the company in this section includes activities related to the production of special manufacturing equipment. In addition, the maintenance personnel should carry out inspections and major overhauls of production resources as scheduled. The last important activity of the maintenance staff is disaster recovery. The development strategy of the enterprise assumes that the maintenance department divides the operation times among the following processes:

- manufacturing of special equipment (MSE) - 30\% of operation time,

- capital repairs and overhauls (CRO) - 30\% of operation times,

- disaster recovery activity (DRA) - $20 \%$ of operation time

- setups and control (SCO) - $20 \%$ of operation time. Only the last two processes belong to the maintenance area of enterprise. It means that the maintenance team will realize $50 \%$ of operation process- es. The monitoring of the maintenance staff activity can be based on ERP system, where all the tasks and events are registered on a daily basis. First, the production resources should be defined (production lines, CNC machines, conveyers, transportation vehicles, etc.). To create master production schedule, some manufacturing resources are already registered in ERP system (MRP II), other resources are defined as fixed assets.

The manufacturing resources registered in ERP database should be described by a set of data, which is useful for maintenance management:

- required frequency of inspections,

- plan and scope of overhauls,

- costs of ownership (exploration, repairs, breakdowns),

- maintenance production order,

- list of spare parts,

- list of maintenance operations,

- technical documentation.

The frequency of inspection is determined by performance requirements of the manufacturing resources. On the basis of the inspections and opinion of operators and maintenance staff, the plan of overhauls is prepared.

The plan includes the general scope of the overhauls (list of tasks, main spare parts, components, materials and professionals). On the basis of the schedule and scope of the renovation, the planned costs are estimated. During the overhaul, the actual costs of materials and operation times are registered. The planned and actual costs of the overhauls should be compared at the end of the project. A model of maintenance acivities in the area of production overhaul is presented in Fig. 1.

The model encompasses maintenance planning, data registration and comparison of planned and actual maintenance costs. The evaluation of maintenance can be based on score methods where the prompt completion of maintenance orders, costs and effectiveness of maintenance are taken into account. The evaluation of maintenance is a very important component of incentive scheme. The score methods enable the evaluation of every result of a maintenance task by a numerical value.

The manager of a maintenance department determines a score for all tasks, not only planned by also not planned (breakdowns). A model of maintenance activities in the area of production breakdowns elimination is presented in Fig. 2. 


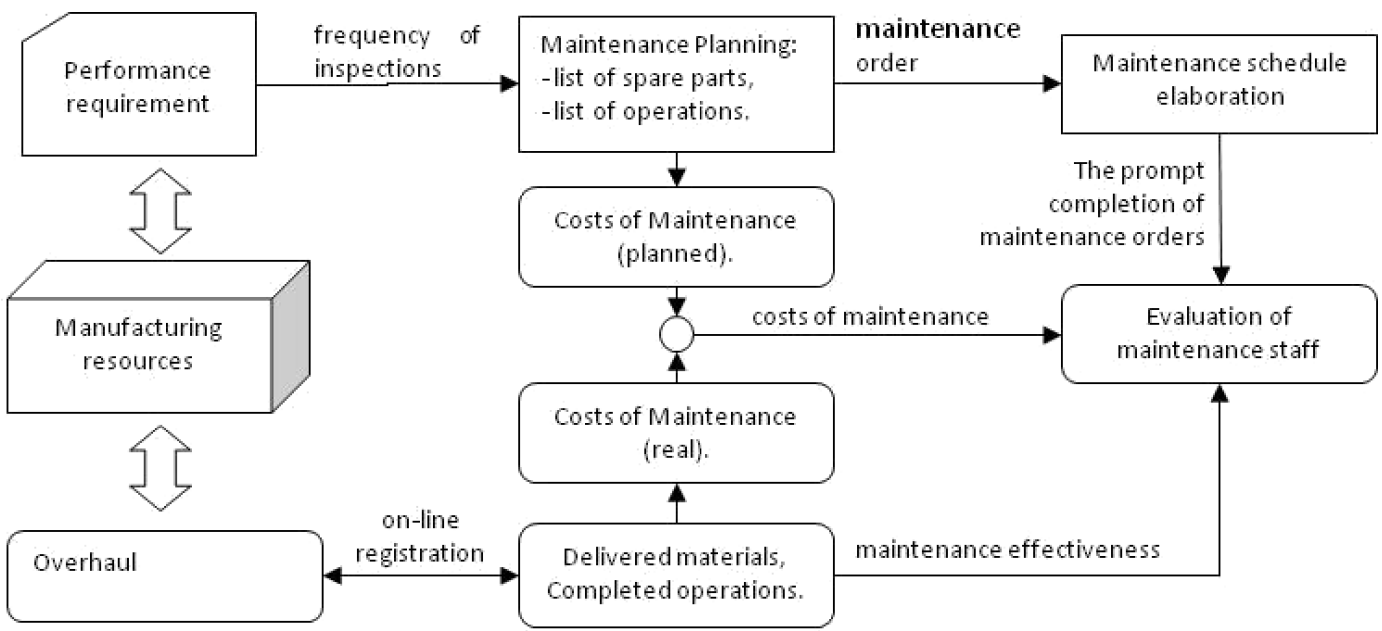

Fig. 1. A model of maintenance activities in the area of production overhaul.

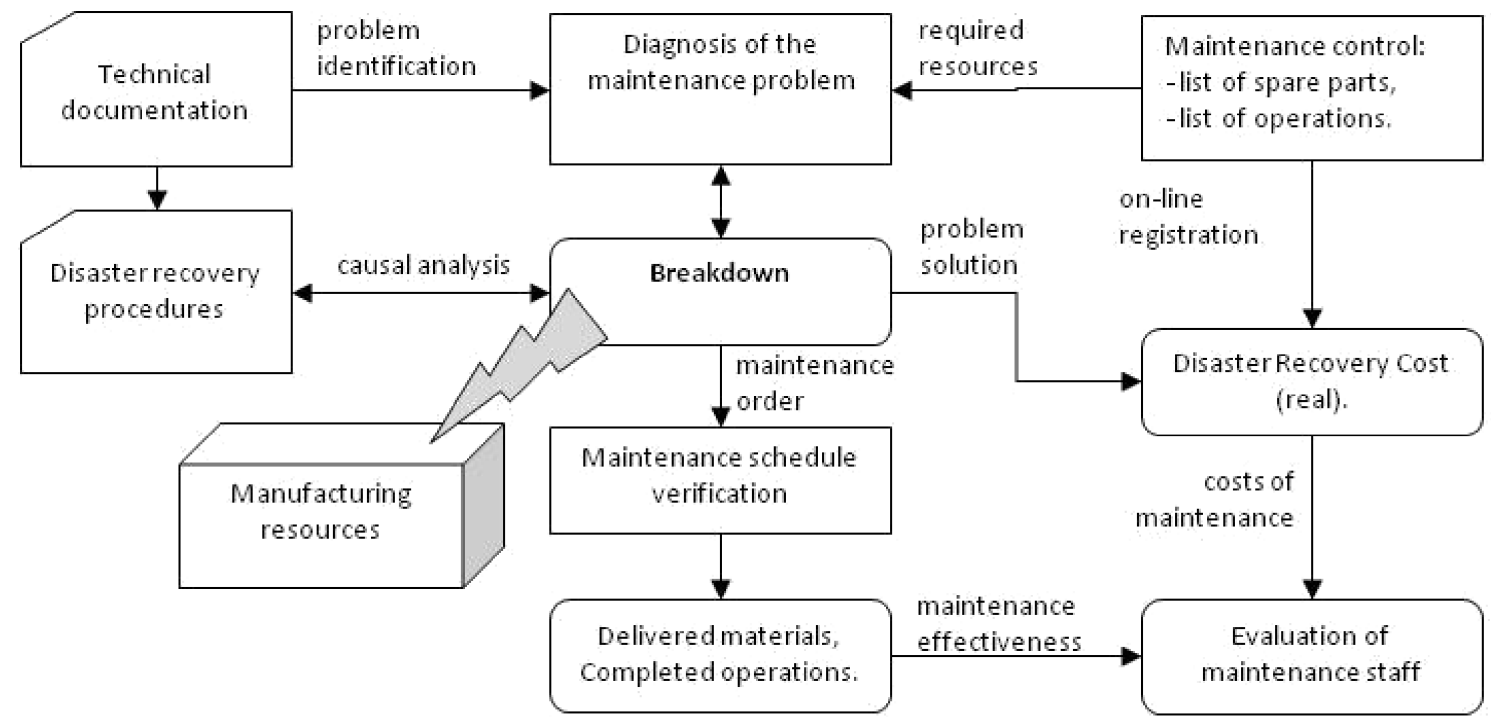

Fig. 2. A model of maintenance activities in the area of production breakdown.

The next important area of maintenance activities are production setups. The setup time is dependent on the following parameters:

- type of production (type of machine, production lines, automation level, etc.),

- training and organization of machine operators and maintenance staff (for example TPM, SMED methodology),

- sequence of production orders (master production schedule),

- batch size.

A model of maintenance activities in the area of production changeover is presented in Fig. 3. On the basis of the proposed models of maintenance activities, a model of maintenance support by ERP system is proposed (see Fig. 4). The model encompasses a set of data, important reports and the main functions of the ERP system which make the maintenance work more efficient. In addition, the model should include information technology and data processing algorithms. To obtain the effective functionality of the ERP system in the area of maintenance, a set of decisions important in the functional area must be supported. The data registered in the ERP database enables development of an algorithm for the evaluation of maintenance workers. The algorithm can automatically calculate bonus salary for every maintenance worker per month. To calculate the bonus salary for maintenance staff, the following aspects should be taken into account:

- individual responsibility for every maintenance task,

- score evaluation of every maintenance task,

- time of maintenance tasks completion,

- overhaul/setup/disaster recovery time. 


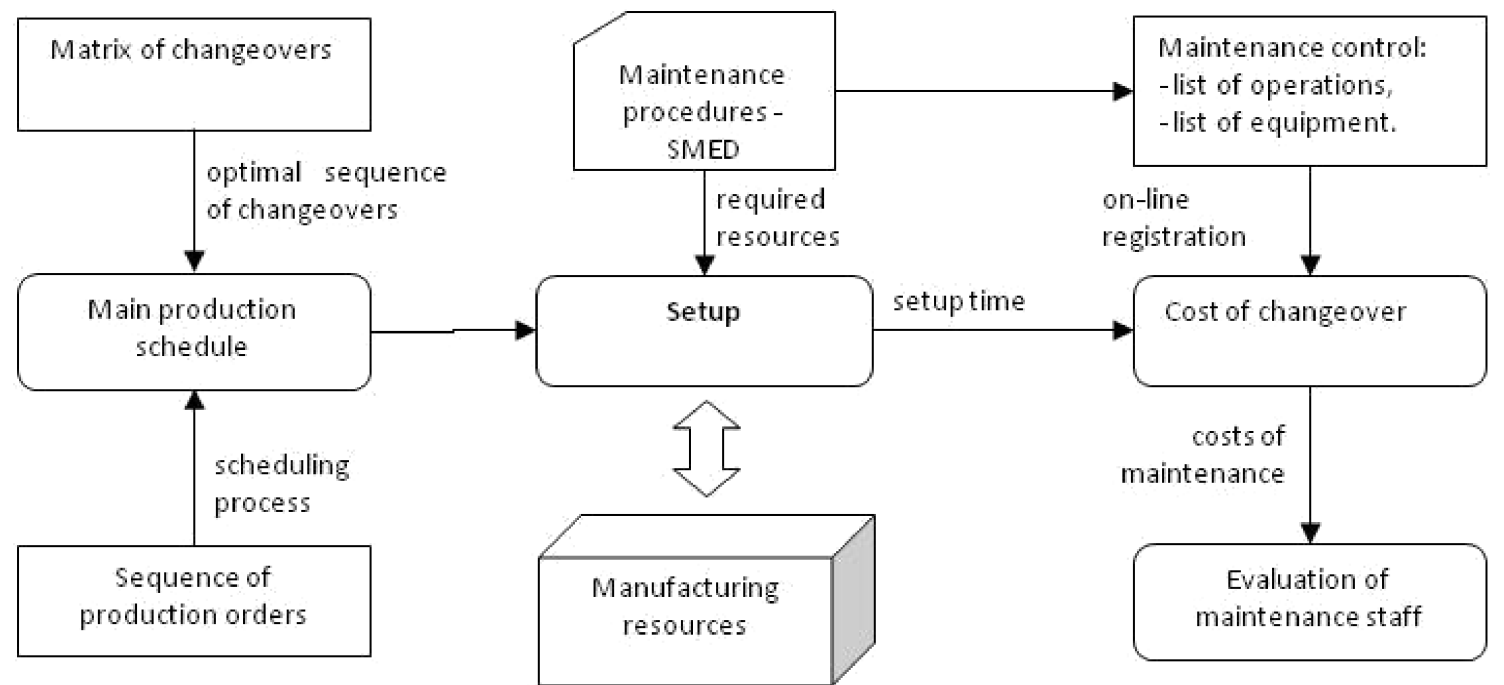

Fig. 3. A model of maintenance activities in the area of production changeover.

- spare parts,

Sets of data

- suppliers of spare parts,

- maintenance operations,

- maintenance workers,

- manufacturing resources,

- production events,

- performance requirement,

- operation times (start, stop,

delay, etc.)

- matrix of changeovers,

- service activities,

- maintenance costs,

- maintenance orders,

- maintenance schedule,

-technical documentation.

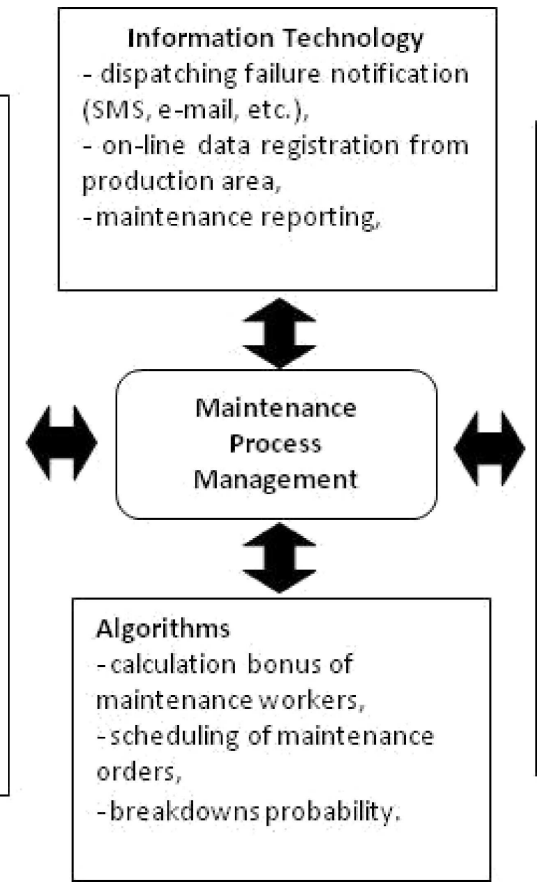

\section{Decisions}

- manufacturing resource

exploration and upgrade,

- size and value of spare parts

warehouse,

- number and qualifications of

workers in maintenance area,

- choice of spare parts suppliers,

- choice of external service,

- choice of maintenance workers,

-score of maintenance orders and

workers,

-frequency of inspections of

manufacturing resources,

-priority of maintenance orders.

Fig. 4. Maintenance process management with ERP systems.

The formula for the maintenance bonus salary calculation can be denoted as follows:

$$
\begin{aligned}
S_{w} & =f_{w}\left(W^{O} \cdot \sum_{(i=1)}^{n} t_{l}^{O} \cdot v_{j}^{O}+W^{S} \cdot \sum_{(j=1)}^{m} t_{j}^{S} \cdot v_{j}^{S}\right. \\
& \left.+W^{R} \cdot \sum_{(k=1)}^{p} t_{k}^{D} \cdot v_{k}^{D}+W^{E} \cdot \sum_{(l=1)}^{r} t_{l}^{E} \cdot v_{l}^{E}\right)
\end{aligned}
$$

where $W^{O}, W^{S}, W^{D}, W^{E}$ - weight value (overhauls, setups, disaster recovery, equipment, respectively), $t^{O}, t^{S}, t^{D}, t^{E}$ - operation time - (overhauls, setups, disaster recovery, equipment, respectively), $v^{O}, v^{S}$, $v^{D}, v^{E}$ - score evaluation (overhauls, setups, disaster recovery, equipment, respectively), $i, j, k, l$-number of maintenance tasks in month (overhauls, setups, disaster recovery, equipment, respectively), $S_{W}-w$ maintenance worker evaluation rate in a period of time, $f_{w}$ - bonus salary rate.

The number and time of setups result directly from main production schedule and setup matrix stored in the ERP system. But maintenance workers have direct influence on the real setup time (implementation and using of TPM methods). 
The score of every task should be kept individually by maintenance or production managers.

The final evaluation of a maintenance employee can be directly calculated into money. The total monthly budget of bonus salary is divided among the maintenance workers on the basis of summary evaluation shares. The presented algorithm was implemented in Alpha company in the same time together with implementation of ERP system in maintenance area.

Table 2 presents maintenance data for one worker registered at the enterprise Alpha during a five-day working week.

Table 2

An example of maintenance evaluation.

\begin{tabular}{l|c|c|c|c|c|c|c}
\hline Day & 1 & 2 & 3 & 4 & 5 & & Total \\
\hline Time [hours] & 0 & 4 & 4 & 0 & 0 & & \\
\hline Score [1-5] & 0 & 5 & 4 & 0 & 0 & & \\
\hline Overhauls $W=3$ & 0 & 20 & 16 & 0 & 0 & 36 & 108 \\
\hline Time [hours] & 3 & 0 & 4 & 0 & 2 & & \\
\hline Score [1-5] & 4 & 0 & 3 & 0 & 3 & & \\
\hline Setups $W=2$ & 12 & 0 & 12 & 0 & 6 & 30 & 60 \\
\hline Time [hours] & 2 & 0 & 0 & 6 & 4 & & \\
\hline Score [1-5] & 3 & 0 & 0 & 4 & 4 & & \\
\hline Disaster recovery $W=1$ & 6 & 0 & 0 & 24 & 16 & 46 & 46 \\
\hline Time [hours] & 3 & 4 & 0 & 2 & 2 & & \\
\hline Score $[1-5]$ & 4 & 4 & 0 & 2 & 3 & & \\
\hline Equipment $W=4$ & 12 & 16 & 0 & 4 & 6 & 38 & 152 \\
\hline & & & & & & & 366 \\
\hline
\end{tabular}

The total evaluation of the employee in question is equal to $S=366$. The bonus salary rate is determined individually for every maintenance employee. A standard work day is 8 hours, which means that an employee can get maximum rate $S_{W}=8$ [hours] $\cdot 5$ [days] $\cdot 5$ [max rate] $\cdot 4\left[W^{E}\right]=800$ points in a week. If maximal bonus salary in a week is $400 €$, than bonus salary rate should be $f_{W}=0.5$. For the example presented in Table $2, S_{w}=0.5 \cdot 366=183 €$.

The data presented in the Table 2 are automatically processed by the ERP system (the motivation system was built-in the ERP system functionality). That enabled to avoid opportunistic behavior of the maintenance staff by the implementation of the system. Implementation of the new motivation system integrated with the ERP system functionality resulted with improving of maintenance staff engagement. The maintenance workers significantly increase activities related to failures prevention and equipment manufacturing (the activities especially supported by the weight values). The main weakness of the system was not taken into account absence of the maintenance workers.

\section{Analysis of maintenance processes}

One of the most popular methods for improvement of maintenance processes in manufacturing enterprises is TPM method, which is part of the Lean Manufacturing philosophy [12]. TPM focuses on preventing breakdowns of manufacturing equipment during the whole production period and seeks full commitment of all workers in all departments, not just maintenance departments. The implementation of TPM in the manufacturing enterprise is based on the following eight pillars [13]:

- Focus Improvement - monitoring utilization level of machine tools and production equipment, and identification of all kinds of waste in the production area.

- Autonomous Maintenance - placing responsibility for proper routine maintenance in the hands of operators by giving them greater "ownership" and increasing their knowledge of the equipment.

- Planned Maintenance - measurement of Mean Time to Repair (MTTR) and Mean Time Between Failure (MTBF) ratios.

- Quality Maintenance - quality improvement of produced goods by introduction of proper tools for quality measurement; technical analysis of particular sub-systems of machine tools and production lines that have a direct impact on the quality and functions of final products.

- Education \& Training - continuously training machine tools operators by the maintenance staff.

- Safety \& Environment - systematically ensuring safe working environment and reduction of potentially dangerous conditions.

- Early Management - anticipative reaction, registering data on production resources and forwarding the requirements to the machine operators and service departments.

- TPM in Office - increasing the amount of information and the efficiency of workflow efficiency concerning machine tools and production lines.

Computerized Maintenance Management Software (CMMS) is often a part of ERP (for example SAP, IFS, Oracle, etc.) or can be easily integrated with external ERP systems. ERP or CMMS systems support maintenance processes and register important data [13]. Maintenance process monitoring in ERP system is based on a maintenance order, which is a key component of maintenance process. The following data describe maintenance orders:

- number of maintenance order,

- manufacturing resource (fixed asset),

- start and end data, 
- type of maintenance order (disaster recovery, setup, overhaul, etc.),

- priority,

- maintenance operation,

- planned and real time of maintenance operations,

- planned and real list of spare parts,

- status of maintenance order (planned, opened, closed, deleted, etc.),

- maintenance tools,

- costs of maintenance order (planned and real).

The analysis of history of maintenance orders enables the analysis of maintenance processes. The life cycle of maintenance order includes the following stages:

- Initiation;

- Plannin;

- Confirmation;

- Beginning;

- Ending;

- Deleting.

Monitoring the life cycle enables the performance evaluation of maintenance orders.

Analyzing the data of the ERP system, where the history of maintenance orders is being recorded, we can generate reports that enable the effec- tive management of maintenance activities. To protect the manufacturing system against breakdowns, the most important preventive decisions should be made. The reports can be generated automatically or on demand, but it is important to determine the frequency of report analysis. For example, a report of breakdowns should be generated and analyzed daily, or even after every work shift.

The data required for the reports can be automatically or manually registered in the ERP database. Table 3 presents manufacturing data on a selected machine.On the basis of the data registered in the ERP database, the activity of the maintenance staff can be evaluated. For example, net operation time can be compared with setup time and the share of the setup time can be calculated. Figure 5 presents the values of the share of setup time in operation time calculated on the basis of the ERP data from Table 3. Because the maintenance activities should be evaluated, it means that, for example, index $v^{s}$ (score - setup evaluation) can be determined every day on the basis of the values of share net operation time and setup time. For example, if the share of setup time in operation time is between $0 \%$ and $20 \%$, the $v^{S}=5$; for interval $21 \%-30 \% v^{S}=4 ; 31 \%-40 \%$

Table 3

Monthly production datasheet - machine X.

\begin{tabular}{|c|c|c|c|c|c|c|c|c|c|c|c|c|c|}
\hline September & Sheet & $\mathrm{m} 2$ & $\mathrm{~m} 2$ & [h] & {$[\mathrm{h}]$} & {$[\mathrm{h}]$} & [h] & {$[\#]$} & {$[\mathrm{min}]$} & $\mathrm{m} 2$ & $\%$ & {$[$ sheet $/ \mathrm{h}]$} & [sheet/h] \\
\hline Day & $\begin{array}{c}\text { Good } \\
\text { products }\end{array}$ & $\begin{array}{c}\text { Good } \\
\text { products }\end{array}$ & $\begin{array}{c}\text { Average } \\
\text { sheet }\end{array}$ & $\begin{array}{c}\text { Gross } \\
\text { operation } \\
\text { time }\end{array}$ & $\begin{array}{c}\text { Net } \\
\text { operation } \\
\text { time }\end{array}$ & $\begin{array}{c}\text { Planned } \\
\text { stop } \\
\text { time }\end{array}$ & $\begin{array}{c}\text { Setup } \\
\text { time }\end{array}$ & $\begin{array}{l}\text { Number } \\
\text { of setups }\end{array}$ & $\begin{array}{c}\text { Average } \\
\text { setup }\end{array}$ & Waste & Waste & $\begin{array}{c}\text { Gross } \\
\text { effective- } \\
\text { ness }\end{array}$ & $\begin{array}{c}\text { Net } \\
\text { effective- } \\
\text { ness }\end{array}$ \\
\hline 30 & 53190 & 63436 & 1.19 & 24.01 & 14.43 & 5.33 & 4.25 & 11.00 & 23.17 & 902.00 & 0.01 & 2215 & 3687 \\
\hline 29 & 49044 & 60130 & 1.23 & 23.86 & 13.16 & 7.30 & 3.40 & 8.00 & 25.47 & 443.67 & 0.01 & 2046 & 3727 \\
\hline 26 & 55314 & 60560 & 1.09 & 23.76 & 14.33 & 5.73 & 3.68 & 8.00 & 27.57 & 942.17 & 0.02 & 2328 & 3859 \\
\hline 25 & 62290 & 53455 & 0.86 & 24.00 & 15.34 & 4.57 & 3.64 & 8.00 & 27.34 & 594.50 & 0.01 & 2595 & 4061 \\
\hline 24 & 39567 & 35897 & 0.91 & 19.86 & 9.95 & 2.79 & 3.15 & 8.00 & 23.60 & 4911.33 & 0.12 & 1646 & 3976 \\
\hline 23 & 32315 & 38998 & 1.21 & 23.90 & 8.68 & 10.34 & 4.74 & 10.00 & 28.46 & 2890.67 & 0.07 & 1352 & 3721 \\
\hline 22 & 44450 & 45172 & 1.02 & 24.03 & 11.84 & 6.79 & 5.40 & 12.00 & 27.02 & 962.00 & 0.02 & 1850 & 3753 \\
\hline 21 & 22318 & 22338 & 1.00 & 7.75 & 5.79 & 1.16 & 0.80 & 2.00 & 24.07 & 532.67 & 0.02 & 2777 & 3856 \\
\hline 20 & 63293 & 61360 & 0.97 & 23.58 & 15.73 & 4.05 & 3.80 & 7.00 & 32.58 & 1067.33 & 0.02 & 2682 & 4022 \\
\hline 19 & 46631 & 51129 & 1.10 & 24.01 & 13.14 & 4.36 & 6.50 & 13.00 & 30.02 & 1194.50 & 0.02 & 1942 & 3548 \\
\hline 18 & 47522 & 38579 & 0.81 & 23.99 & 12.97 & 4.56 & 6.45 & 12.00 & 32.27 & 724.50 & 0.02 & 1981 & 3664 \\
\hline 17 & 49154 & 46809 & 0.95 & 24.01 & 13.09 & 5.93 & 4.99 & 8.00 & 37.40 & 671.00 & 0.01 & 2048 & 3756 \\
\hline 16 & 32970 & 36066 & 1.09 & 23.95 & 10.04 & 8.90 & 3.84 & 6.00 & 38.42 & 1137.00 & 0.03 & 1377 & 3284 \\
\hline 15 & 57611 & 64356 & 1.12 & 23.98 & 15.14 & 4.56 & 4.28 & 8.00 & 32.10 & 1899.00 & 0.03 & 2403 & 3805 \\
\hline 14 & 36959 & 47267 & 1.28 & 14.38 & 9.03 & 2.93 & 2.42 & 5.00 & 28.99 & 1060.67 & 0.02 & 2457 & 4093 \\
\hline 13 & 11838 & 16799 & 1.42 & 7.44 & 4.76 & 1.07 & 1.61 & 3.00 & 32.14 & \begin{tabular}{|l|}
803.83 \\
\end{tabular} & 0.05 & 1564 & 2486 \\
\hline 12 & 48115 & 38982 & 0.81 & 21.52 & 12.49 & 5.77 & 3.27 & 5.00 & 39.18 & 542.50 & 0.01 & 2235 & 3851 \\
\hline 11 & 61599 & 67716 & 1.10 & 26.58 & 15.60 & 5.29 & 5.68 & 15.00 & 22.73 & 2016.50 & 0.03 & 2317 & 3948 \\
\hline 10 & 50118 & 42881 & 0.86 & 24.03 & 12.15 & 5.98 & 5.85 & 14.00 & 25.07 & 1134.50 & 0.03 & 2086 & 4127 \\
\hline 9 & 67144 & 78373 & 1.17 & 23.98 & 16.21 & 4.96 & 2.80 & 6.00 & 28.04 & 1295.50 & 0.02 & 2800 & 4141 \\
\hline 8 & 64328 & 73994 & 1.15 & 23.74 & 15.72 & 3.46 & 4.56 & 10.00 & 27.35 & 1721.83 & 0.02 & 2701 & 4092 \\
\hline 6 & 46481 & 43601 & 0.94 & 23.60 & 13.05 & 4.85 & 5.69 & 11.00 & 31.06 & 951.83 & 0.02 & 1937 & 3563 \\
\hline 5 & 56213 & 40819 & 0.73 & 21.95 & 14.09 & 3.65 & 4.21 & 10.00 & 25.24 & 2277.83 & 0.05 & 2349 & 3990 \\
\hline 4 & 57629 & 53243 & 0.92 & 20.01 & 14.03 & 2.12 & 3.86 & 9.00 & 25.73 & \begin{tabular}{|l|}
934.67 \\
\end{tabular} & 0.02 & 2879 & 4108 \\
\hline 3 & 56315 & 54056 & 0.96 & 24.00 & 13.93 & 4.78 & 5.28 & 9.00 & 35.19 & 691.00 & 0.01 & 2346 & 4041 \\
\hline 2 & 48516 & 67906 & 1.40 & 23.98 & 12.29 & 6.83 & 4.85 & 9.00 & 32.35 & 1286.00 & 0.02 & 2023 & 3946 \\
\hline 1 & 61157 & 67769 & 1.11 & 23.99 & 14.75 & 4.72 & 4.46 & 8.00 & 33.44 & 1003.00 & 0.01 & 2550 & 4147 \\
\hline
\end{tabular}




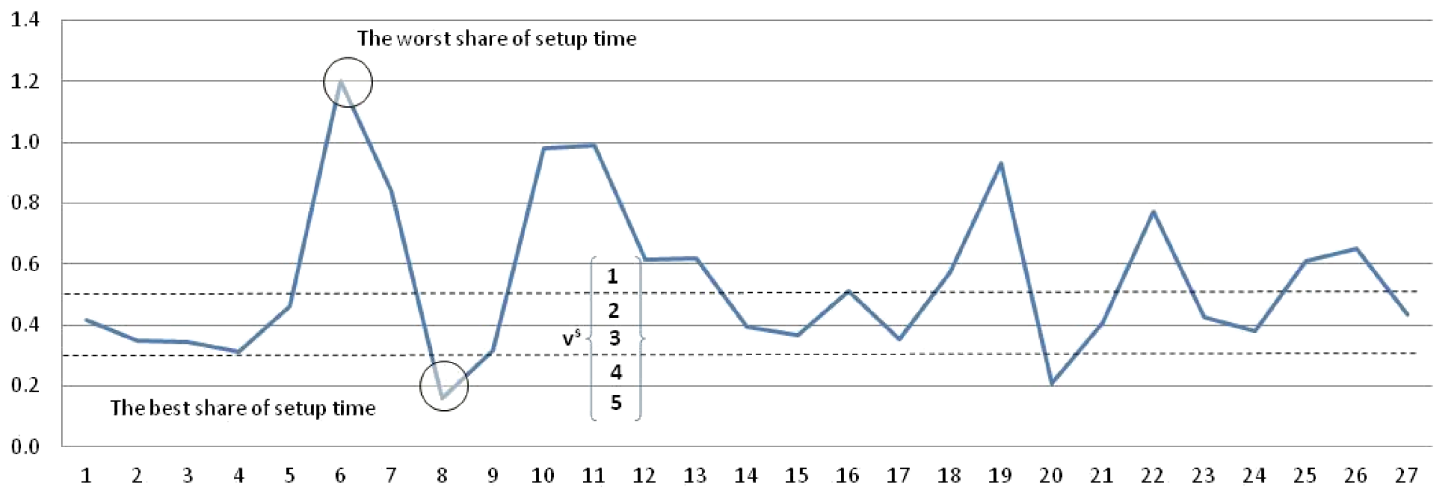

Fig. 5. The share of setup time in operation time.

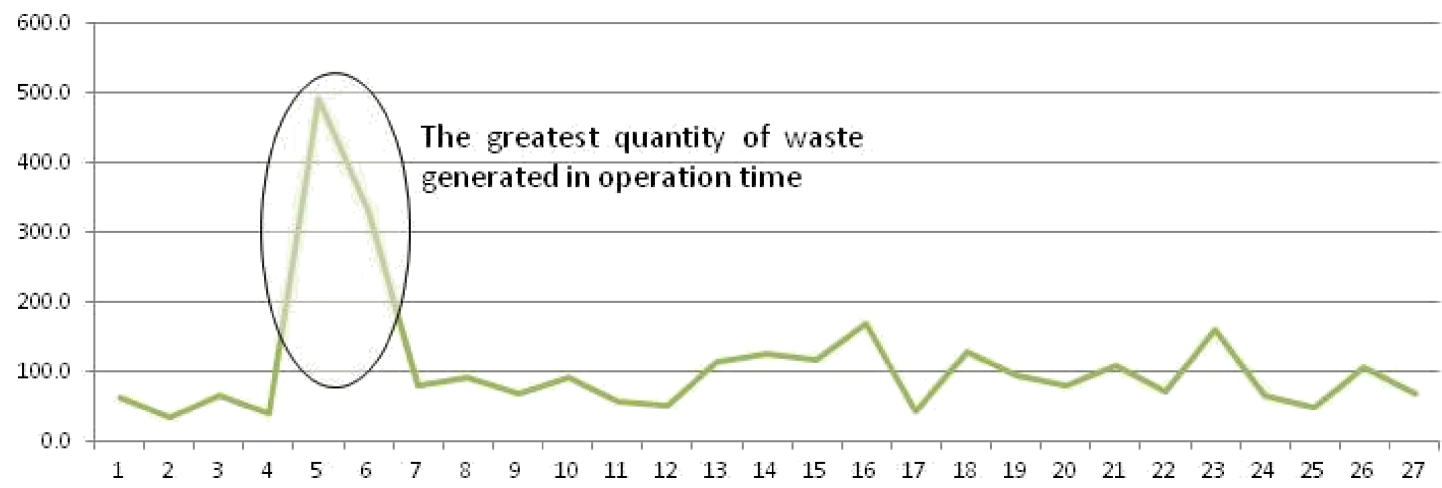

Fig. 6. The waste generated in the net operation time.

$v^{S}=3 ; 41 \%-50 \% v^{S}=2 ; 51 \%-60 \% v^{S}=1$; and if the value is greater than $60 \%$, the rate $v^{S}=0$. The graph in Fig. 5 shows that the maintenance staff were most efficient in the area of setups on days 8 and 20 , and least efficient on days 6, 10, 11, 19 and 22 .

In the same way another score evaluation can be automatically calculated. For example, planned stop time enables the evaluation of effectiveness of the maintenance staff in the area of overhaul. The amount of waste generated in the production process depends on good or bad adjustment of the machine. The overhaul of the machine includes the adjustment time. Figure 6 shows the waste generated in the net operation time.

The analysis of the production data shows that within 3 days $(5,6,7)$ not only the setup time was too long, but also the generated waste was extremely high. It means that the maintenance tasks carried out on those days must be carefully analyzed.

I order to analyze the maintenance process, the structure of the process in a manufacturing enterprise should be defined and the methodology for maintenance process analysis should be proposed. A proposed structure of maintenance process is presented in Fig. 7. The structure encompasses maintenance activities such as: overhauls, breakdowns prevention and removing, changeover management and production of tools and special equipment.

The structure also includes maintenance resources: tools and equipment, spare parts, procedures and documentation, maintenance works, etc. The maintenance processes evaluation is based on the evaluation of the production processes and the proper execution of the master production plan. The thin arrows in Fig. 7 represent the data flow in the area of maintenance and production.

The effective monitoring of maintenance processes, communication between maintenance and production and reporting of the maintenance activities enable the evaluation of the total maintenance efficiency.

Today, in complex manufacturing systems, management of maintenance area without the support of ERP systems is impossible. 


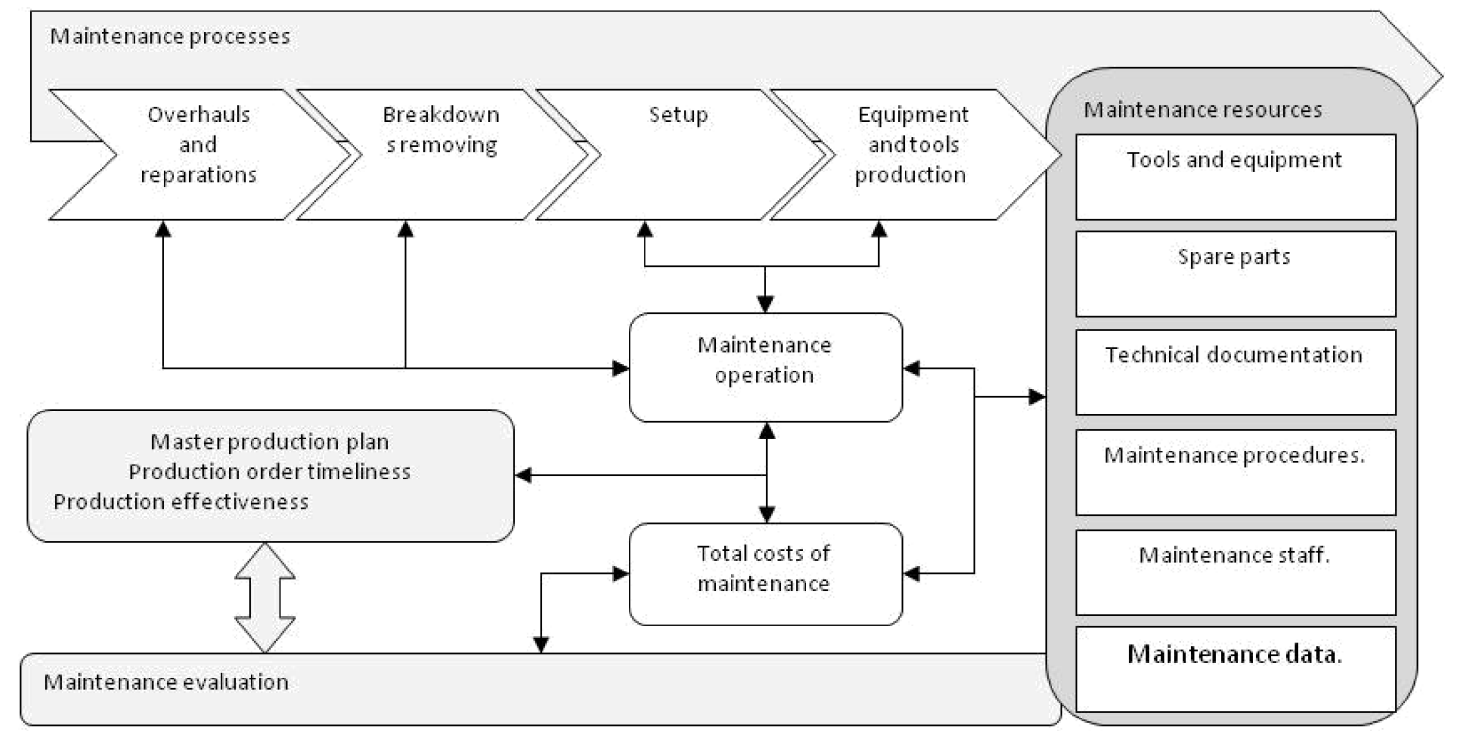

Fig. 7. The structure of maintenance process.

\section{The methodology of ERP implementation in the maintenance area}

Implementation of ERP system in the area of maintenance enables us to analyze the efficiency of maintenance activities, monitor and report maintenance events such as overhauls, breakdowns, setups, etc. and evaluate maintenance activities. The higher the level of automation of a production area, the more important maintenance processes are. In the areas of maintenance and tool management, the CMM modules are implemented generally at the end of ERP implementation project. Data registration related to maintenance events requires direct integration of an ERP system with the production line control system, work centre, or implemented Manufacturing Execution System. To evaluate the performance of maintenance processes, the master production plan must be executed. It means that the MRP and MRP II procedures must be executed, master production schedule is generated by the ERP system and the delays or failures of production processes are registered. The next important aspect of the implementation of the ERP system in the maintenance area is the design of communication, monitoring and reporting of maintenance activities. Generally, the ERP system must improve maintenance project management. On the basis of the registered data from the production system and the monitoring procedures, an evaluation system of maintenance staff should be designed. On the basis of the registered production events and the time analysis the salary bonus algorithm for the maintenance workers should be determined. The system will be effective if the salary bonus can be calculated automatically. If the motivation system has been properly designed, the maintenance staff will not only be continuously improving for more productive work, but they will also demand investments and improvement of manufacturing resources, or proper maintenance warehouse inventory (required spare parts in the maintenance warehouse). For the maintenance activities, the procedure should be constructed and implemented as the ERP functions. For example, for breakdowns removing, the following steps of maintenance activities can be determined:

- Automatic recording of the time of machine breakdown in ERP system.

- Recording the type of breakdown - checking the causes of breakdown based on a closed list of possibilities. Every cause is described by a set of symptoms - the selection of the type of breakdown is made by machine operators.

- Forwarding the information according to its priority to the maintenance dispatcher as an e-mail or text message, and automatic recording in ERP system of the time the maintenance service is reported.

- Appointing a maintenance worker (or team of maintenance workers) to eliminate the breakdown.

- Recording additional data on the breakdown in ERP database - determining the scope of maintenance project and the list of resources.

- Specifying and checking accessibility of replacements and required cooperation - determining the repairs schedule. 


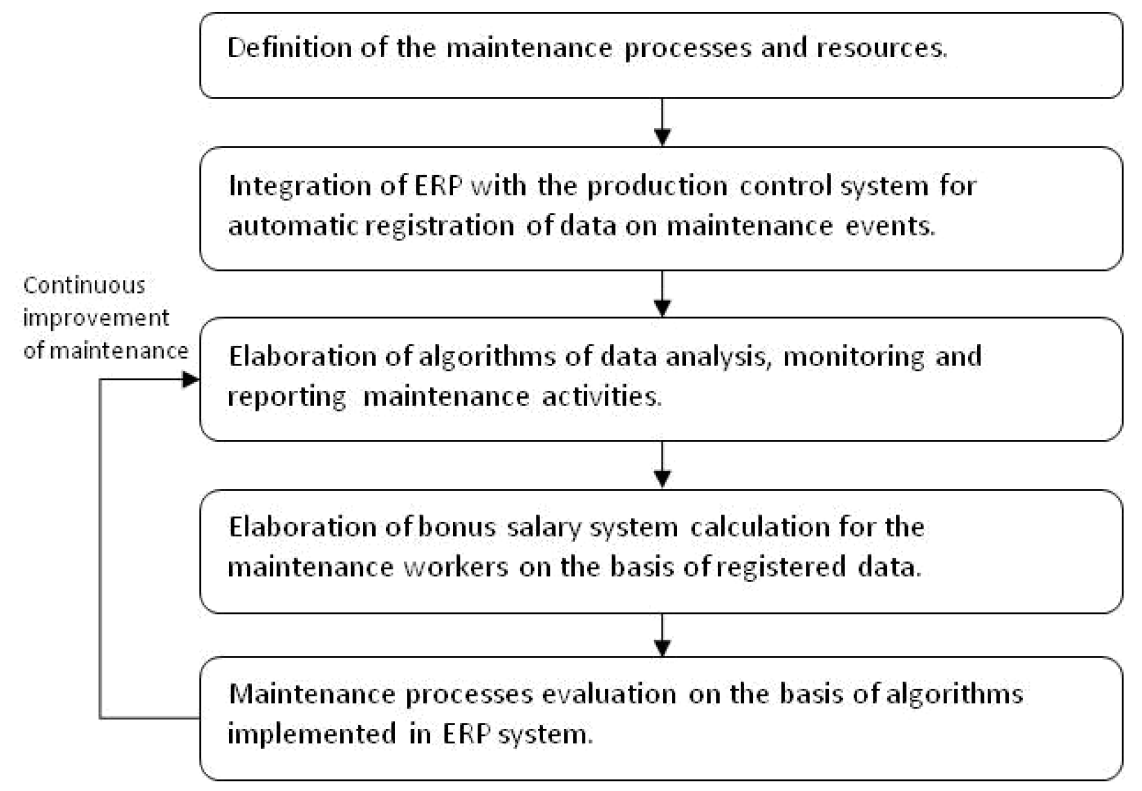

Fig. 8. A methodology of ERP system implementation in the maintenance area.

- Information for production planning - introducing changes into the production schedule [15].

- Repairs and machine testing.

The methodology of ERP system implementation in the maintenance area is presented in Fig. 8. The main assumption of the proposed methodology was closely integration of ERP with maintenance staff motivation system to improve effectiveness of the maintenance processes. In the first step of the ERP system implementation in maintenance area, the maintenance processes and resources should be defined. The data described the maintenance resources and processes should be defined and registered in the ERP system. In the next step, an algorithm of maintenance activity data monitoring, analysis and reporting should be constructed (which ratios are important, how often the data should be registered, what are the maintenance priorities, etc.). The set of registered data is important for the next step of the methodology - it means construction of effective bonus salary system. The data registered in ERP system enables to calculate automatically the bonus salary for the maintenance workers, who can control every day financial results of their operational work.

\section{Conclusions}

Production maintenance is a very important area, especially for highly automated industry branches. The effective management of maintenance staff is difficult because some of the realized tasks cannot be planned (time of breakdowns or overhauls). The proposed methodology of ERP system implementation in the area of production maintenance integrates monitoring of the maintenance tasks performance with the motivation system of maintenance workers. The systems of the maintenance staff evaluation based on the QEE rates are helpful, but too simple. In order to produce the effect of continuous improvement of maintenance activities, the algorithm of maintenance processes evaluation must change along with the changes in the production requirements. The motivation system of maintenance staff should be adjusted to the company strategy. For example, if prevention is the most important index, the bonus salary can be dependent on the middle time between failures (MTBF). The proposed methodology enables the maintenance workers to monitor the daily evaluation of their activities and the level of bonus salary. The prototype system is implemented in a manufacturing company that produces prefabricates for building industry.

\section{References}

[1] Morton N.A., Hu Q., Implications of the fit between organizational structure and ERP: A structural contingency theory perspective, International Journal of Information Management, 28, 391-402, 2008.

[2] Kans M., An approach for determining the requirements of computerized maintenance management systems, Computers in Industry, 59, 1, 32-40, January, 2008. 
[3] Kłos S., Evaluation methodology of ERP system implementation in manufacturing enterprises, Zielona Góra, Oficyna Wydawnicza Uniwersytetu Zielonogórskiego, 263, 2010.

[4] Barbera L., Crespo A., Viveros P., Stegmaier R.I., Advanced model for maintenance management in a continuous improvement cycle: integration into the business strategy, International Journal of System Assurance Engineering and Management, 3, 1, 4763, March 2012.

[5] Muchiri P., Pintelon L., Gelders L., Martin H., Development of maintenance function performance measurement framework and indicators, Int. J. Production Economics, 131, 295-302, 2011.

[6] Bass B.M., Avolio B.J., Improving Organizational Effectiveness Through Transformational Leadership, Sage Pub. Inc., 1994.

[7] Van Horenbeek A., Pintelon L., Muchiri P., Maintenance optimization models and criteria, Int. J. Syst. Assur. Eng. Manag., 1 (3), 189-200, July-Sept. 2010.

[8] Rosqvist T., Laakso K., Reunanen M., Value-driven maintenance planning for a production plant, Reliability Engineering and System Safety, 94, 1, 97-110, January 2009.

[9] Horenbeek A., Pintelon L., Muchiri P., Maintenance optimization models and criteria, Internatio- nal Journal of System Assurance Engineering and Management, 1, 3, 189-200, September 2010.

[10] Mosaddar D., Shojaie A., A data mining model to identify inefficient maintenance activities, International Journal of System Assurance Engineering and Management, 4, 2, 182-192, June 2013.

[11] Shum Yu-Su, Gong D.-Ch., The application of genetic algorithm in the development of preventive maintenance analytic model, The International Journal of Advanced Manufacturing Technology, 32, 1-2, 169-183, February 2007.

[12] Imai M., Kaizen, Kaizen Institute Polska, MT Biznes Ltd., 2007.

[13] Laszkiewicz M., Maintenance is a strategic business asset [in Polish: Utrzymanie ruchu to strategiczne aktywa firmy], Trade Media International [Inżynieria \& Utrzymanie Ruchu Zakładów Przemysłowych], Warszawa, March 2005.

[14] Schutz J., Rezg N., Léger J.-B., An integrated strategy for efficient business plan and maintenance plan for systems with a dynamic failure distribution, Journal of Intelligent Manufacturing, 24, 1, 87-97, February 2013.

[15] Yang Z.M., Djurdjanovic D., Ni J., Maintenance scheduling in manufacturing systems based on predicted machine degradation, J. Intell. Manuf., 19, 87-98, 2008. 